\title{
TO STUDY THE EFFECTS OF SEQUENTIAL LOADING AND CONSTRUCTION LIVE LOAD ON DIFFERENT MULTISTOREY RCC FRAMES AND SLABS
}

\author{
Ravipratap Singh Chandrawat \\ Civil Engineering Department \\ IPS Academy, \\ Institute of Engineering and Science, \\ Indore, M.P. India
}

\author{
Rajesh Chaturvedi \\ Civil Engineering Department \\ IPS Academy, \\ Institute of Engineering and Science, \\ Indore, M.P. India
}

\begin{abstract}
Generally, it is assumed in linear static analysis that full loads are applied once the whole structure is constructed completely. But in real life, Structure is subjected to complex loading like material stackings, formwork loads, labor weights, equipment loads and other construction live loads etc. these loads are applied in every stage of construction process of structure. That's why they have a huge impact on structures and its members. These early effects on members which have not gain its full strength might be dangerous during and after construction of structures. These early effects on members are of irreversible in nature and increases with service life of structures. Which is mostly ignored by engineers in the past during analysis of structure. The analysis of structure during each stage of construction is known as construction sequence analysis. The present work makes an attempt to analyze the members of different RCC multi-storey structures for construction sequence analysis on ETABS. It is mainly divided into two parts. In the first part three models of different building configurations are used to analyze the effects of CSA on beam, column, internal \& external transfer beam and floating column. And in the second part the fourth model is used to analyze the effect of CSA on slab and extended to different aspect ratio slabs.
\end{abstract}

Keywords - Construction stage analysis, Sequential loading, Staged construction, Construction live load.

\section{INTRODUCTION}

Over the years, multistory structures are analyzed with assumptions that all the probable loads like dead load, live load and lateral loads are applied on the frame at given instant using the single step analysis or known as conventional analysis. But in real life the structure is constructed in various stages and the stability of structure constantly varies at each of these stages. However, this effect has been ignored by engineers in the past. To include this effect properly the structure has to analyzed through step by step construction procedure in accordance with the sequential application of self-weight of members. This phenomenon is known as construction stage analysis. It is also known as construction sequence analysis is a Non-linear static form of analysis. Which takes into account the concept of incremental loading. This method is more accurate and practical in real life as it considers the loads at their actual time of application and order of member casting. Hence construction stage analysis should be carried out for precise analysis of the structure. In the past Chakrabarti et al.(1978) examined the effect of self-weight during the construction process of a building. Choi and Kim (1985) also dealt with effect of column shortening under dead load during construction only and paid less attention to excess construction loads. they used "one floor at a time" analysis approach for problem. Chang-Koon Choi (1992) used a simplified approach known as "Correction factor Method (CFM)" considering only dead loads. From the previous literature it is clear that very less attention was given to the loading and sequence of member casting during construction. Which leads to instability of structure. Therefore, this paper deals with various responses like axial force, shear force, bending moment, deflection, crack width and crack spacing in various members during sequential construction.

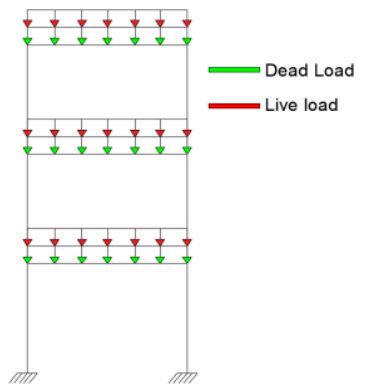

Fig. 1. Conventional analysis 


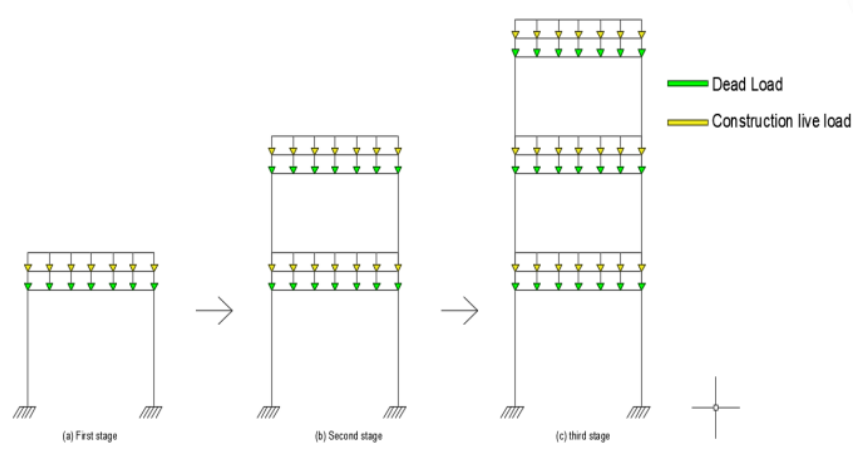

Fig. 2. Construction stage analysis

The effects develop at the early stages of the construction process continue to evolve considerably after the structures are built. these early damages are plastic in nature and are mostly irreversible. Which gets worst with service life of the structures.

This study is mainly focused on how different structural members like beam, column, slab, transfer girder and floating columns behaves during each stage of construction by using ETABS software. Following two types of models are used -

- Construction stage analysis on frame.

- Sequential loading on slab.

1.1 Construction stage analysis on frame-

Three models are used to analyze the effects of stage wise construction on frame. These effects due to CSA on beam, column, transfer beam and floating column are compared with conventional analysis.

\subsection{Sequential loading on slab-}

The load effects arise due to the sequence of construction are termed as sequential loading. These effects are mainly due to self-weight of freshly poured concrete floor above, construction live load (Labor, equipment, material stacking etc.), formwork and their position on the slab.

\section{RESEARCH METHODOLOGY}

\subsection{Problem formulation:}

1. Modelling of four completely different buildings with $\mathrm{fck}=25 \mathrm{MPa}$ and fy = $415 \mathrm{MPa}$ using ETABS software.

2. First three models are analyzed for linear static analysis and then for construction stage analysis by completely using ETABS software.

- Model A - A G+10 RCC building frame

- Model B - A G+10 RCC frame with internal floating columns and transfer beam

- $\quad$ Model C - A G+10 RCC frame with external floating columns and transfer beam

3. Fourth model is analyzed for linear static analysis and then for construction stage analysis by manual hand calculation and partially using ETABS software.

- Model D - A G+2 RCC building with slab

4. Different aspect ratio slabs (length/width) varies from 1.0 to 2.0. are analyzed same as above.

\subsection{Models Specifications:}

Model-A

\begin{tabular}{|c|c|}
\hline Parameters & Specification \\
\hline Plan dimension & $16 \times 16 \mathrm{~m}$ \\
\hline No. of stories & $\mathrm{G}+10$ \\
\hline Floor height & $3.15 \mathrm{~m}$ \\
\hline Beam B1 & $200 \times 400 \mathrm{~mm}$ \\
\hline Column C1 & $300 \times 400 \mathrm{~mm}$ \\
\hline
\end{tabular}

Model-B

\begin{tabular}{|c|c|}
\hline Parameters & Specification \\
\hline Plan dimension & $16 \times 16 \mathrm{~m}$ \\
\hline No. of stories & $\mathrm{G}+10$ \\
\hline Floor height & $3.15 \mathrm{~m}$ \\
\hline Beam B1 & $200 \times 400 \mathrm{~mm}$ \\
\hline Beam B2 & $200 \times 400 \mathrm{~mm}$ \\
\hline Beam B3 & $350 \times 800 \mathrm{~mm}$ \\
\hline Column C1 & $300 \times 400 \mathrm{~mm}$ \\
\hline Column C2 & $300 \times 400 \mathrm{~mm}$ \\
\hline
\end{tabular}

Model-C

\begin{tabular}{|c|c|}
\hline Parameters & Specification \\
\hline Plan dimension & 14 X $24 \mathrm{~m}$ \\
\hline No. of stories & $\mathrm{G}+10$ \\
\hline Floor height & $3.15 \mathrm{~m}$ \\
\hline Beam B1 & $200 \times 400 \mathrm{~mm}$ \\
\hline Beam B2 & $400 \times 900 \mathrm{~mm}$ \\
\hline Column C1 & $300 \times 400 \mathrm{~mm}$ \\
\hline Column C2 & $400 \times 600 \mathrm{~mm}$ \\
\hline
\end{tabular}
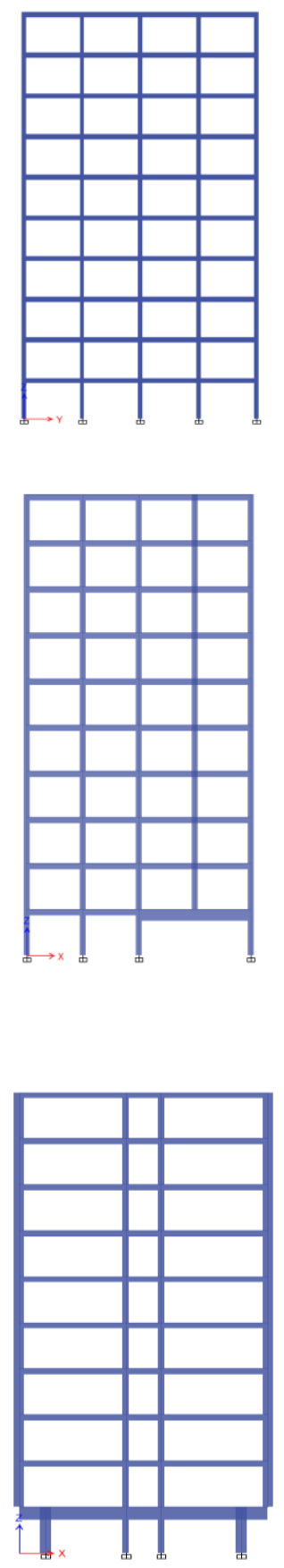
Model-D

\begin{tabular}{|c|c|}
\hline Parameters & Specification \\
\hline Plan dimension & 4 X 6 m \\
\hline No. of stories & $\mathrm{G}+2$ \\
\hline Floor height & $3 \mathrm{~m}$ \\
\hline Beam B1 & $200 \times 500 \mathrm{~mm}$ \\
\hline Beam B2 & $200 \times 500 \mathrm{~mm}$ \\
\hline Column C1 & $300 \times 400 \mathrm{~mm}$ \\
\hline Slab depth & $150 \mathrm{~mm}$ \\
\hline Slab Mesh size & $200 \times 200 \mathrm{~mm}$ \\
\hline
\end{tabular}

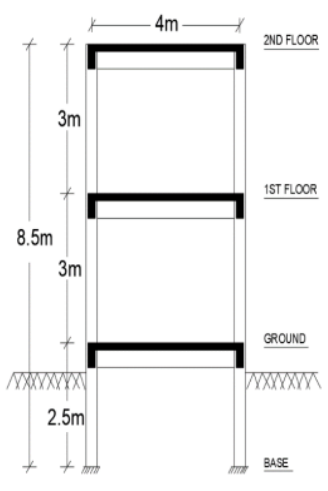

\subsection{Linear Static analysis -}

Linear Static analysis or conventional method is the default analysis method that used to analyze structures. Compared with non-linear analysis, linear analysis is an efficient method of solving a structure as it assumes the structure to behave in an elastic manner.

Linear static analysis has following assumptions:

- Behavior of the structure should be linear.

- The loading is static.

Table -1 Loads to be considered

\begin{tabular}{|c|c|}
\hline Load type & Details \\
\hline Live load & 2kN/m² (as per IS875-II) \\
\hline Table -2 Load Combinations \\
\hline Case & Combinations \\
\hline Case 1 (Serviceability) & DL+LL \\
\hline Case 2 (Ultimate/Collapse) & $1.5 \mathrm{DL}+1.5 \mathrm{LL}$ \\
\hline
\end{tabular}

Ast Calculations - Steel Reinforment should be provided as per bending moments calculated by linear static analysis.

$$
\text { Ast }=\frac{0.5 \text { fck b d }}{\mathrm{fy}}\left(1-\frac{\sqrt{1}-4.6 * M}{\mathrm{fck} \mathrm{b} \mathrm{d}^{2}}\right)
$$

Deflection:

$$
\Delta \mathrm{e}=\frac{5 \mathrm{WL} 4}{384 \mathrm{EI} \text { eff }}=\frac{5 \mathrm{ML} 2}{48 \mathrm{EI} \text { eff }}
$$

\section{Crack Width:}

By IS 456 -

$$
\mathrm{W}_{\mathrm{cr}}=\frac{3 \mathrm{a}_{\mathrm{cr}} \varepsilon_{\mathrm{m}}}{1+\frac{2(\mathrm{acr}-\mathrm{Cmin})}{\mathrm{h}-\mathrm{x}}}
$$

By Desayi \& Kulkarni -

$$
\mathrm{W}_{\max }=\mathrm{K} . \mathrm{R} . \mathrm{fs} \sqrt{I}_{\mathrm{I}}
$$

By Orenstein and Nawy -

$$
\mathrm{W}_{\max }=2.8 \times 10^{-5} \cdot \mathrm{R} \cdot \mathrm{fs} \sqrt{\mathrm{I}}
$$

By ACI Committee -

$$
\mathrm{W}_{\max }=\mathrm{k} \cdot \beta \cdot \mathrm{fs} \sqrt{\mathrm{I}}
$$

\section{Crack Spacing:}

By Desayi \& Kulkarni -

Crack spacing in Direction 1 -

$$
\mathrm{a} 1=\frac{\mathrm{kt} * \mathrm{ft} * \text { Actl }}{(\Pi * \emptyset 1 * \mathrm{~kb} * \mathrm{fb} / \mathrm{S} 1)+(\emptyset 2 * \mathrm{fbb} / \mathrm{S} 2)}
$$

Crack spacing in Direction 2 -

$$
\mathrm{a} 2=\frac{\mathrm{kt} * \mathrm{ft} * \text { Act2 }}{(\Pi * \emptyset 2 * \mathrm{~kb} * \mathrm{fb} / \mathrm{S} 2)+(\emptyset 1 * \mathrm{fbb} / \mathrm{S} 1)}
$$

\subsection{Construction stage analysis -}

In actual practice dead load due to the each structural components and finishing items are imposed in separate stages as the structures are constructed story by story. Accordingly, the stability of frame varies at every construction stage. Even during construction freshly placed concrete floor is supported by previously cast floor by formwork. Obvioulsy, results obtained by conventional analysis will be unsuitable. Therefore, the frame should be analyzed at each construction stage taking into account with variation in loads. This phenomena is known as construction stage analysis.

Various parameters should be considered in construction stage analysis -

1- Number of stories in each construction group.

2- Load pattern and their scale factor.

3- Each Stage data.

- Add structure.

- Remove structure.

- Load objects if added.

- Change sections.

4- Age at additional days.

5- Stage name and numbering.

6- Duration days.

To perform construction stage analysis on Model D, acting loads like construction live load, formwork load and freshly placed concrete floor loads are manually calculated and then applied on model using ETABS 17 software. The reason is 


\section{International Journal of Engineering Applied Sciences and Technology, 2020 \\ Vol. 4, Issue 11, ISSN No. 2455-2143, Pages 84-91 \\ Published Online March 2020 in IJEAST (http://www.ijeast.com)}

that ETABS can calculate stage wise loads for beams and columns but it can't calculate formwork, wet floor slab load on previously cast floor. So we have to do it manually. We will also check results of different aspect ratio slabs.

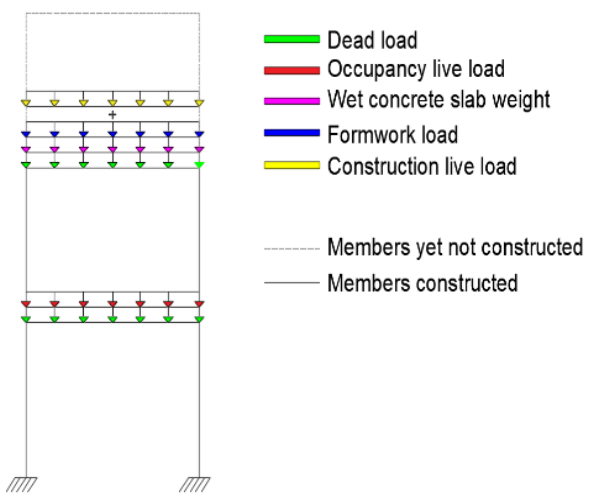

Fig. 3. Sequential loading on slab

\section{Loadings calculations -}

The freshly placed concrete floor weight and worker with equipments weight transfers to previously cast floor (10-15 days old) by wooden or steel props. We are assuming a condition where 5 workers are standing on a area of $1 \mathrm{~m}^{2}$ with equipments on $\mathbf{1 . 5}$ aspect ratio slab of $4 \times 6 \mathrm{~m}$. And distance between prop is $\mathbf{1 m}$ for easy accessebility and movement.

Wet slab load $=\mathbf{3 . 9} \mathbf{~ k N} / \mathbf{m}^{2}$

Formwork load $=\mathbf{0 . 5} \mathbf{~ k N} / \mathrm{m}^{2}($ IS 14687)

Constrcution live load $=\mathbf{3 . 8} \mathbf{~ k N} / \mathbf{m}^{2}$ (Manual)

\section{Load on beams -}

$$
\text { Total load }=8.2 \mathrm{kN} / \mathrm{m}^{2}
$$

$$
\begin{aligned}
& \text { Beam B1 }=\mathbf{2 6 . 8} \mathbf{k N} \\
& \text { Beam B2 }=\mathbf{4 0 . 2} \mathbf{k N}
\end{aligned}
$$

\section{Load on columns -}

All Columns $\mathrm{C} 1=\mathbf{4 2 . 5} \mathbf{~ k N}$

Load on props -

$$
\text { Prop P1 }=8.2 \text { kN }
$$

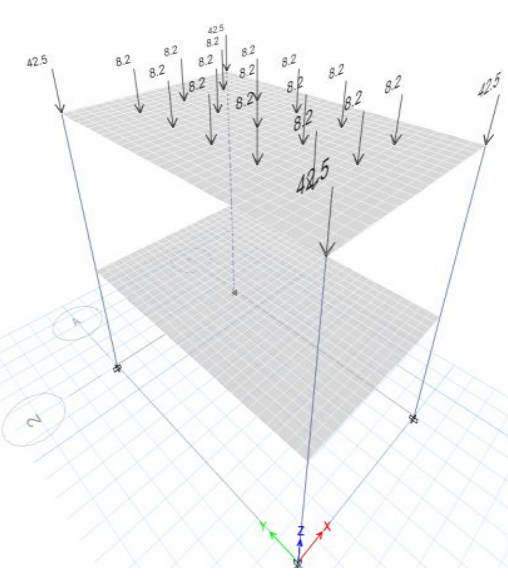

Fig. 4. 3D view of loads on first floor slab

\section{RESULT AND DISCUSSION}

In the present discussion, Results of each member are compared with all other models. To see how members responses with different building configuration when they analyzed with conventional analysis and the compared with stage analysis.

1. Normal beam - As we can see in the graph, B.M. at support values of normal beam of Model $\mathrm{A}, \mathrm{B}$ and $\mathrm{C}$ are lesser and B.M. at mid-span values of normal beam of Model A, B and $\mathrm{C}$ are higher for stage analysis as compared to conventional analysis.

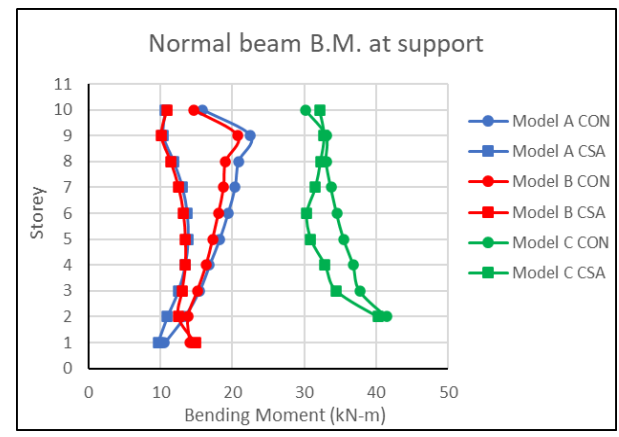

Fig. 5. B.M. at support in Normal beams

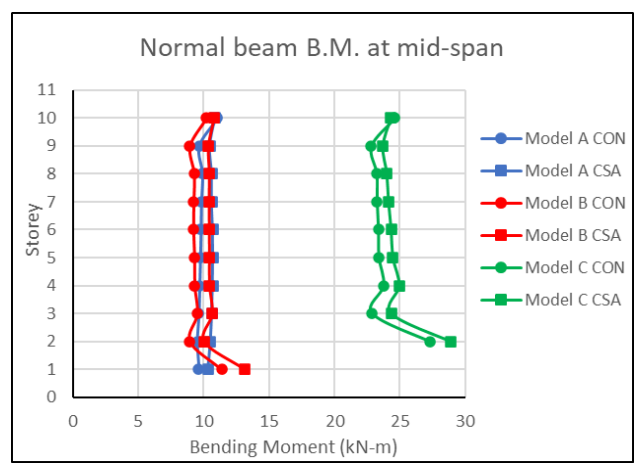

Fig. 6. B.M. at mid-span in Normal beams

Shear force values of normal beam of Model A and B are less and in Model C, S.F. value is high for stage analysis as compared to conventional analysis.

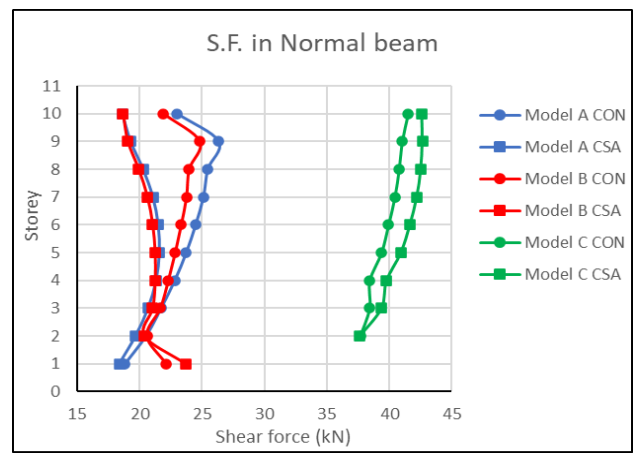

Fig. 7. Shear Force in Normal beams 


\section{International Journal of Engineering Applied Sciences and Technology, 2020 \\ Vol. 4, Issue 11, ISSN No. 2455-2143, Pages 84-91 \\ Published Online March 2020 in IJEAST (http://www.ijeast.com)}

Deflection value of normal beam of all models are high for stage analysis as compared to conventional analysis.

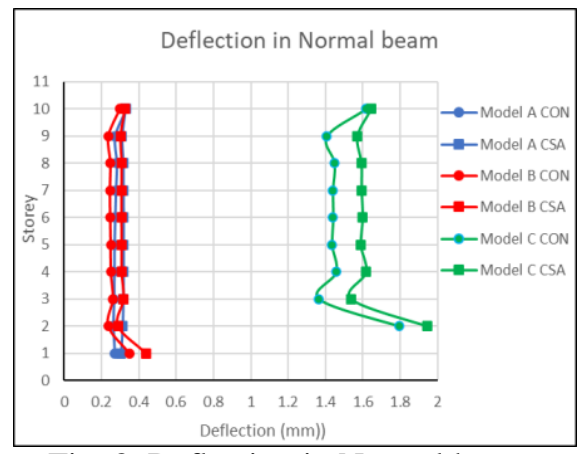

Fig. 8. Deflection in Normal beams

2. Normal column - From the results, Axial force values of normal column of Model A, B and C are low for stage analysis as compared to conventional analysis.

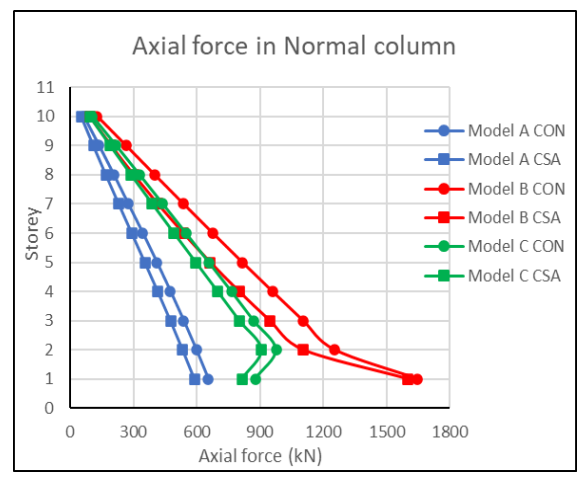

Fig. 9. Axial force in Normal columns

Bending Moments in Normal column of Model A, B and C decreases for stage analysis as compared to conventional analysis.

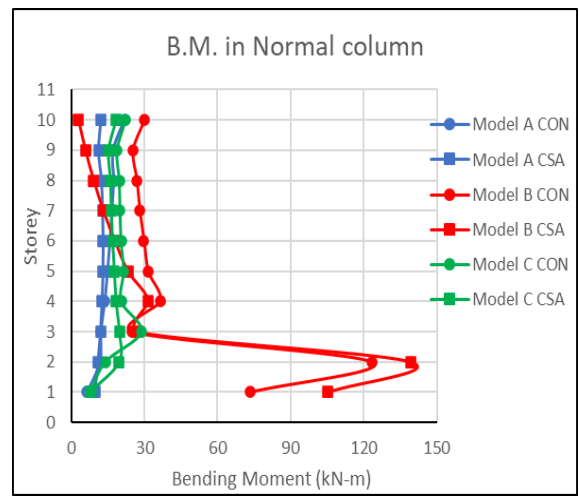

Fig. 10. B.M. in Normal columns

Shear force values of Normal column of Model A, B and C also decreases for stage analysis as compared with conventional analysis.

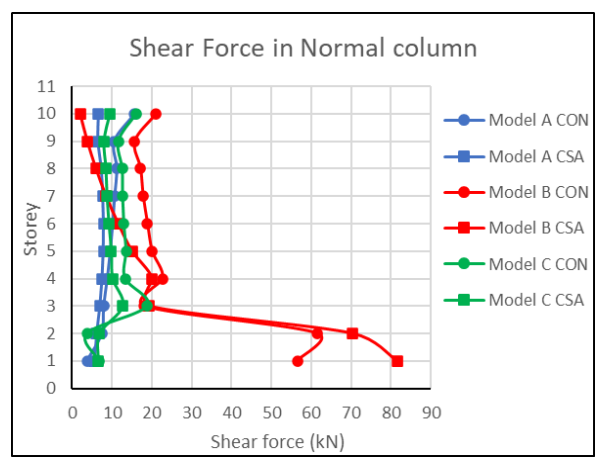

Fig. 11. Shear force in Normal column

Axial deformation values of Normal column of Model A, B and $\mathrm{C}$ also decreases for stage analysis as compared with conventional analysis.

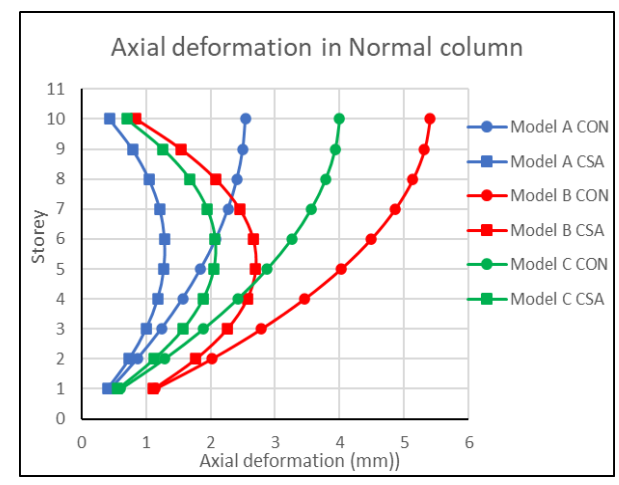

Fig. 12. Axial deformation in Normal columns

3. Transfer beam - Bending moment at support and at midspan of Internal transfer beam of Model B increases for stage analysis as compared to conventional analysis. B.M at support and at mid-span of External transfer beam of Model $\mathrm{C}$ decreases for stage analysis as compared to conventional analysis.

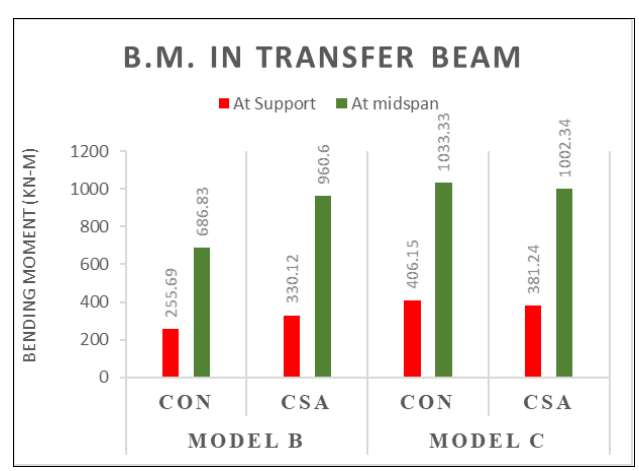

Fig. 13. B.M. in transfer beams

Shear force in Internal transfer beam of Model B increases for stage analysis as compared with conventional analysis. And 
Shear force in External transfer beam of Model C decreases for stage analysis as compared with conventional analysis.

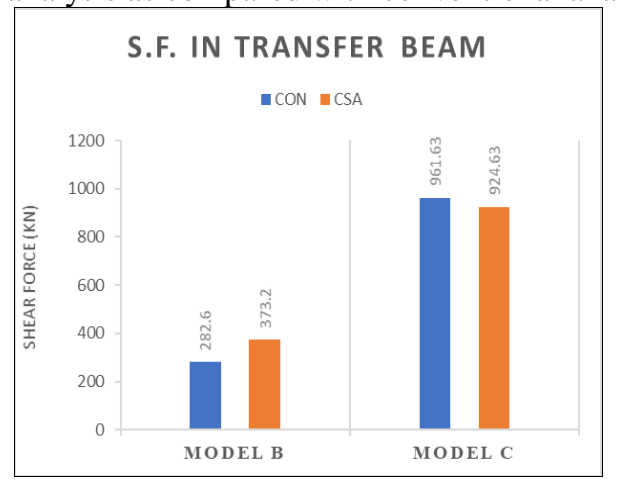

Fig. 14. S.F. in transfer beams

Deflection value of Internal transfer beam of Model B also increases for stage analysis as compared with conventional analysis

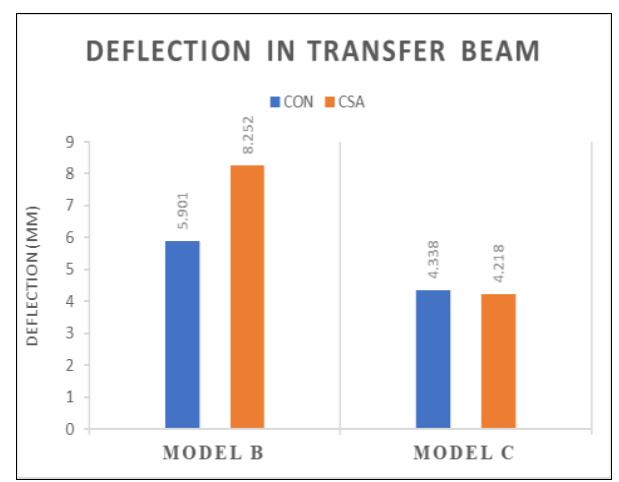

Fig. 15. Deflection in transfer beams

4. Floating column - Axial force in Internal floating column of Model B increases for stage analysis as compared with conventional analysis. And axial force in External floating column of Model C decreases with stage analysis as compared with conventional analysis.

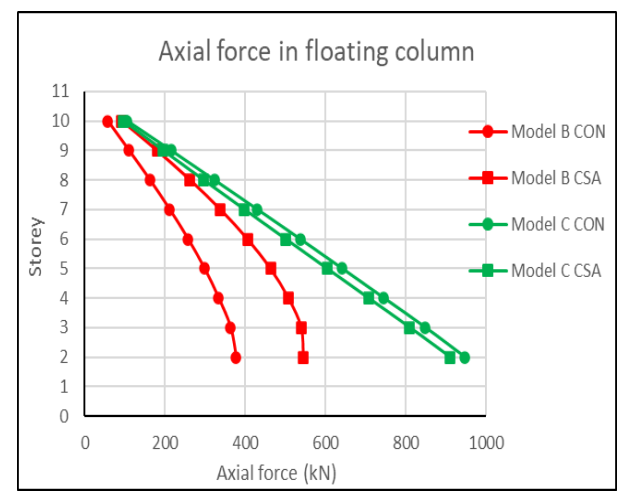

Fig. 16. Axial force in floating columns

Bending moments in Internal floating column of Model B decreases for stage analysis as compared with conventional analysis. And B.M. in External floating column of Model C increases for stage analysis as compared with conventional analysis.

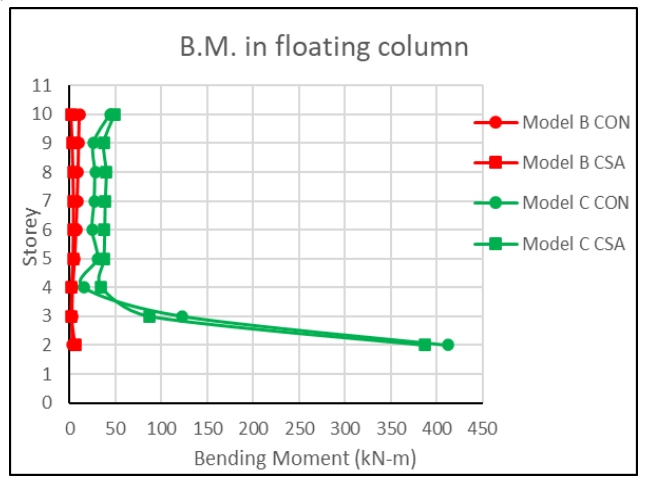

Fig. 17. B.M. in floating columns

Shear force in Internal floating column of Model B decreases for stage analysis as compared with conventional analysis. And Shear force in External floating column of Model C increases for stage analysis as compared with conventional analysis.

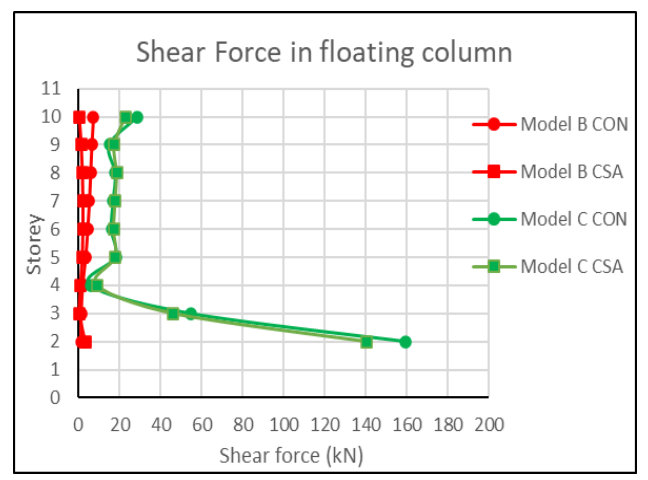

Fig. 18. S.F. in floating columns

Axial deformation in Internal floating column of Model B decreases for top floor column and increases for bottom floor column for stage analysis as compared with conventional analysis. And axial deformation in External floating column of Model C decreases for stage analysis as compared with conventional analysis.

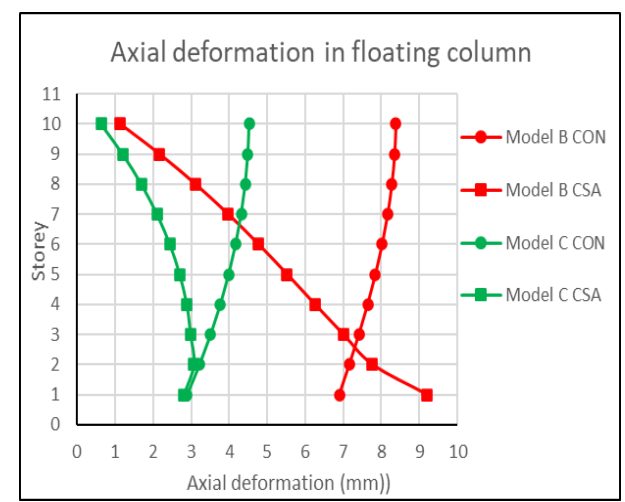

Fig. 19. Axial deformation in floating columns 
5. Slab - Deflection in all slabs increases with increase in slab aspect ratio for stage analysis as compared with conventional analysis.

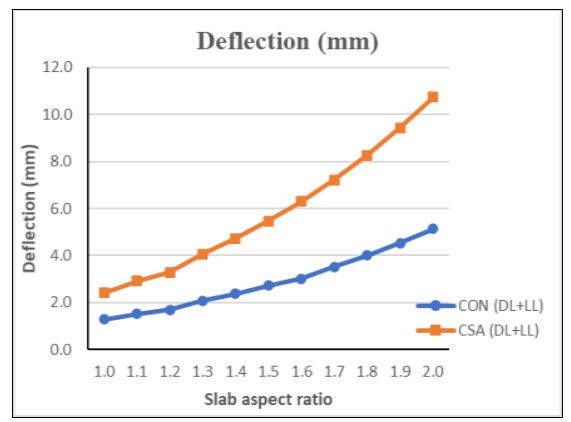

Fig. 20. Deflection in Slabs

Crack width in all different aspect ratio slabs increases with increase in slab aspect ratio. And crack width also increases for stage analysis as compared with conventional analysis.

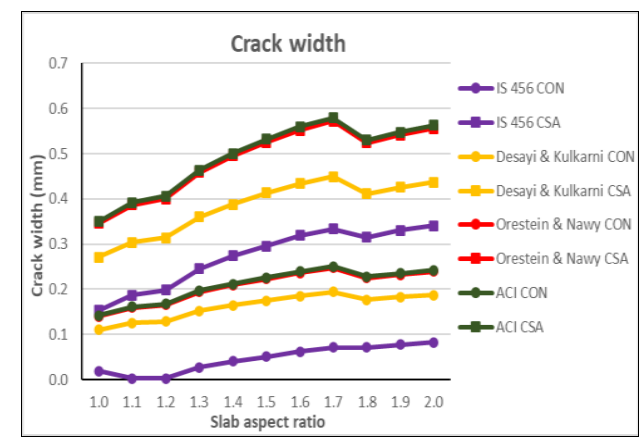

Fig. 21. Crack width of Slabs

Spacing between cracks in both Short (X) Direction and Long (Y) direction decreases with increase in slab aspect ratio. And it is also decreasing for stage analysis as compared with conventional analysis.

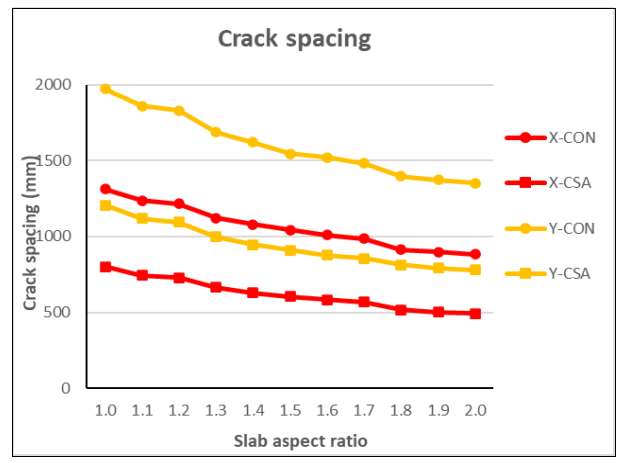

Fig. 22. Crack spacing in Slabs

\section{CONCLUSION}

4.1 The various conclusion are as follows:

1. From CSA of Normal beam, we came to the conclusion that due to stage wise construction of structure we should design these normal beams for lesser bending moment and shear force.

2. From the results of stage analysis of Normal column, it can be concluded that the we should design these normal columns for lesser axial force, bending moment, shear force and axial deformation.

3. From CSA of two different transfer beams, we concluded that Internal transfer beams should be designed for higher bending moment, shear force and deflection. And External transfer beams should be design for lesser bending moment, shear force and deflection.

4. From the results of two different floating columns, it is concluded that Internal floating column should be designed for higher axial force and lesser bending moment, shear force and axial deformation. And External floating column should be designed for lesser axial force, bending moment, shear force and axial deformation.

5. From stage analysis of different slab, it is concluded that slab should be designed for higher span moments, deflection, crack width and spacing.

6. In different aspect ratio slabs moments, deflection, crack width increases with increase in aspect ratios. And these responses also increase for stage analysis. And spacing between cracks reduces with high slab aspect ratio and CSA. Crack width crossing limiting value of $0.3 \mathrm{~mm}$ by IS 456 for higher aspect ratio slabs and CSA. that is quite dangerous for service life of structures.

7. Additional formula for two-way displacement and two-way crack width must be incorporated in the Indian code.

8. Cracks formed in slabs during the early stage of construction may have serious impact with time. These early cracks during the initial life of the slabs lead to corrosion of reinforcement. Which gets worst during service life of slab.

\section{REFERENCE}

[1] Chakrabarti S. C., Nayak G. C. \& Agarwala S. K. (1978). Effect of sequence of construction in the analysis of multistoreyed building frame, Building and Environment, 13(1), (Pg1-6).

[2] Choi C. K., Chung H. K., Lee D. G. \& Wilson E. L. (1992). Simplified building analysis with sequential dead loads-CFM. Journal of Structural Engineering, 118(4), (Pg944-954).

[3] Choi C. K. \& Kim E. D. (1985). Multistory frames under sequential gravity loads. Journal of Structural Engineering, 111(11), (Pg2373-2384).

[4] Das G. G. \& KI D. P. (2016). Comparison of Conventional and Construction Stage Analysis of a RCC Building. International Journal Of Science Technology \& Engineering, 3(3).

[5] Desayi P. \& Kulkarni A. B. (1976). DETERMINATION OF MAXIMUM CRACK WIDTH IN TWO-WAY 


\section{International Journal of Engineering Applied Sciences and Technology, 2020 \\ Vol. 4, Issue 11, ISSN No. 2455-2143, Pages 84-91 \\ Published Online March 2020 in IJEAST (http://www.ijeast.com)}

REINFORCED CONCRETE SLABS. Proceedings of the Institution of Civil Engineers, 61(2), (Pg343-349).

[6] Dinar Y., Rasel M. M., Chowdhury M. J. A. \& Ashraf M. A. (2014). Chronological construction sequence effects on reinforced concrete and steel buildings. Int J Eng Sci, 3, (Pg52-63).

[7] Ha T. \& Lee S. (2013). Advanced construction stage analysis of high-rise building considering creep and shrinkage of concrete. In the 2013 World Congress on Advances in Structural Engineering and Mechanics (ASEM13),(Pg 2139-2147).

[8] Hirde S. K. \& Bhosale P. R. (2018). Effect of Sequential Construction on Multistoreyed Building.

[9] Karshenas S. \& Ayoub H. (1994). Construction live loads on slab formworks before concrete placement. Structural safety, 14(3), (Pg155-172).

[10] Liu X., Chen W. F. \& Bowman M. D. (1985). Construction load analysis for concrete structures. Journal of Structural Engineering, 111(5), (Pg1019-1036).

[11] Murthy T. S. (2016). Comparison of Linear Static Analysis and Construction Sequence Analysis on Multistorey Building with RC Floating Column Resting on RC and Composite Transfer Girders. International Journal of Engineering Trends and Technology, 36(7), (Pg343-346).

[12] Naxane K. Y., Vairagade M. L. \& Bhaskar M. G. B. (2017). Construction Sequence Analysis of Multistoried RCC Building.

[13] Nayak S. S., Kumar R. \& Sonparote R. S. (2014). Effect of Staged Construction Analysis On Seismic Design And Performance Of RC Buildings. 15th SEE.

[14] Orenstein G. S. \& Nawy E. G. (1970). Crack Width Control in Reinforced Concrete Two-Way Slabs Subjected to a Uniformly Distributed Load. In Journal Proceedings (Vol. 67, No. 1), (Pg57-71). 